Cahiers $d u$ MONDE RUSSE

\section{Cahiers du monde russe}

Russie - Empire russe - Union soviétique et États indépendants

\title{
Alexandre Vatline, Larissa Malachenko, éds., Dessine-moi un bolchevik
}

\section{Christophe Barthélémy}

\section{(2) OpenEdition}

\section{Journals}

Édition électronique

URL : https://journals.openedition.org/monderusse/6957

DOI : 10.4000/monderusse. 6957

ISSN : $1777-5388$

Éditeur

Éditions de l'EHESS

\section{Édition imprimée}

Date de publication : 28 décembre 2008

Pagination : 769-770

ISBN : 978-2-7132-2197-2

ISSN : $1252-6576$

Référence électronique

Christophe Barthélémy, "Alexandre Vatline, Larissa Malachenko, éds., Dessine-moi un bolchevik », Cahiers du monde russe [En ligne], 49/4 | 2008, mis en ligne le 24 décembre 2009, consulté le 02 septembre 2022. URL : http://journals.openedition.org/monderusse/6957 ; DOI : https://doi.org/ 10.4000/monderusse.6957

Ce document a été généré automatiquement le 2 septembre 2022.

Tous droits réservés 


\title{
Alexandre Vatline, Larissa Malachenko, éds., Dessine-moi un bolchevik
}

\author{
Christophe Barthélémy
}

\section{RÉFÉRENCE}

Alexandre VATLINE, Larissa MALACHENKO, éds., Dessine-moi un bolchevik. Les

caricaturistes du Kremlin, 1923-1937. Traduit du russe et de l'anglais, préface de François-Xavier Nérard. Paris : Tallandier, 2007, 223 p.

1 Aleksandr Vatlin, professeur à l'Université de Moscou (MGU), et Larissa Malašenko, historienne et archiviste au RGASPI (Rossijskij gosudarstvennyj arhiv social'no-političeskoj istorii - Archives d'État de Russie d'histoire politique et sociale), ont rassemblé dans cet ouvrage plus d'une centaine de caricatures de dirigeants soviétiques extraites des archives du parti. Ce qui fait l'intérêt de ces caricatures n'est pas leur valeur artistique, plutôt faible dans l'ensemble, mais l'identité des auteurs, eux-mêmes dirigeants du parti. Croqués lors des interminables réunions du PCUS, ces dessins circulaient entre hiérarques jusqu'à devenir pour certaines de véritables cadavres exquis.

2 La première partie rassemble des caricatures des principaux dirigeants du parti, en regard de leurs portraits photographiques. Les charges jouent naturellement sur la déformation d'un trait physique, comme l'embonpoint de Zinov'ev, la barbe de Dzeržinskij, le nez de Mikojan, la taille de Kossër... D’autres procédés sont utilisés par les caricaturistes : dans un bestiaire d'animaux plutôt malfaisants, Buharin devient renard porcin, Vorošilov oiseau, Trockij lion, Pjatakov renard... Les auteurs aiment aussi croquer leurs sujets en évoquant l'Ancien Régime : Kalinin se retrouve tsar, Dzeržinskij saint Jean-Baptiste, Stalin gendarme d'Empire. Trockij non plus n'échappe pas à la caricature : ce juif errant, affublé d'une guitare, qui traverse l'Europe occidentale en 
tournant le dos à une URSS dont la frontière est symbolisée par une muraille, c'est bien lui.

3 La deuxième partie est plus innovante puisque les auteurs essaient de décrypter les rapports de force à l'intérieur du parti à l'aide des caricatures. Les images sont plus grinçantes, l'ironie, somme toute assez bon enfant, cède la place à une satire violente : Stalin, knout en main, s'apprête à fouetter des opposants ayant déjà baissé le pantalon avec veulerie. À quelques mois des purges, le sinistre n'est pas loin. Les auteurs utilisent aussi certains dessins pour tenter de compléter les comptes rendus très lacunaires de certaines séances du Politburo et documenter les problèmes des années 1920 et 1930 : éducation, ravitaillement, politique économique, transports... Peu ou pas de question internationale, les seules allusions concernent des opposants accusés de collusion avec le capitalisme américain. Selon les auteurs, alors que les caricatures des années 1920 ciblaient l'opposition, parfois violemment, celles des années 1930 stigmatisent des traits communs à tous; comme si les caricaturistes manifestaient une indulgence certaine pour leurs modèles : les nomenklaturistes parodiant la nomenklatura. Les auteurs y voient le signe de cette solidarité des élites soviétiques qui finira par irriter en haut lieu jusqu’à " devenir un catalyseur des grandes purges».

Précisons enfin que la vulgarité n'est pas absente, comme dans un dessin mettant à la torture le commissaire du peuple aux Finances. L'annotation de la main de Stalin faisant référence aux ordalies médiévales y rajoute une note triviale et sinistre.

L'ouvrage se termine sur le récit en images de deux réunions historiques : le congrès dit « des vainqueurs » de 1934 et le plenum dit « des condamnés » de février-mars 1937. Dans ces dessins, la caricature se teinte de tragique. Les opposants encore en vie sont contraints à l'autocritique, mais, au-delà du trait plutôt violent et grossier, suinte la peur d'une nomenklatura qui craint de se retrouver en position d'accusée. C'est sur l'arrestation du dernier caricaturiste Valerij Mežlauk, président du Gosplan et membre du bureau politique, arrêté en décembre 1937 et exécuté en juillet 1938, que se clôt ce roman graphique collectif du stalinisme. 